Arq. Bras. Med. Vet. Zootec., v.67, n.3, p.855-863, 2015

\title{
Efeito alcalinizante da solução de Ringer com lactato em ovelhas sadias e acidóticas
}

\author{
[Alkalinizing effect of lactated Ringer's solution in healthy and acidotic sheep] \\ M. Cosenza ${ }^{1}$, P.F.V. Pereira ${ }^{2}$, F.T.N.M.A. Romão ${ }^{2}$, K.K.M.C. Flaiban ${ }^{2}$, L.I. Fernandes ${ }^{2}$, \\ R.G. Gargano ${ }^{2}$, J.A.N. Lisbôa ${ }^{2 *}$ \\ ${ }^{1}$ Centro Universitário Filadélfia - UniFil - Londrina, PR \\ ${ }^{2}$ Universidade Estadual de Londrina - UEL - Londrina, PR
}

\section{RESUMO}

O estudo teve o objetivo de testar a hipótese de que o efeito alcalinizante da solução de Ringer com lactato (SRL) pode ser maior nos animais portadores de acidose metabólica do que nos sadios, como consequência da necessidade de retorno ao equilíbrio. Seis ovelhas receberam a SRL em volume correspondente a $10 \%$ do peso corporal, administrada por infusão contínua intravenosa, durante quatro horas, em duas condições definidas: enquanto eram saudáveis e após a indução experimental de acidose láctica ruminal aguda (ALRA). Amostras de sangue venoso e de urina foram colhidas em quatro momentos: antes do início da infusão, na metade do volume infundido, ao término da infusão e duas horas após. Foram determinados valores de $\mathrm{pH}$ sanguíneo e urinário, de $\mathrm{pCO}_{2}, \mathrm{HCO}_{3}{ }^{-}$e $\mathrm{BE}$ no sangue, de $\mathrm{Na}^{+}$, $\mathrm{K}^{+}, \mathrm{Cl}^{-}$, SID, AG, PPT, A $\mathrm{A}_{\text {tot }}$ e lactato L no plasma, e das excreções fracionadas urinárias de $\mathrm{Na}^{+}, \mathrm{K}^{+}, \mathrm{Cl}^{-}$e lactato L. A SRL provocou hemodiluição, mas não interferiu nos equilíbrios eletrolítico e acidobase das ovelhas sadias. Apesar de eficaz para reverter a desidratação, não foi capaz de corrigir a acidose metabólica presente após a indução da ALRA.

Palavras-chave: terapia com fluidos, acidose metabólica, equilíbrio acidobase, equilíbrio eletrolítico

\begin{abstract}
The aim of this study was to investigate if the alkalinizing effect of lactated Ringer's solution (LRS) is greater in animals with metabolic acidosis than in healthy ones, as a result of the need to restore acidbase balance. LRS was intravenously infused in a volume corresponding to $10 \%$ of body weight, continously during four hours, in two definite conditions in the same six ewes: when they were healthy and after experimentally induced acute rumen lactic acidosis (ARLA). Venous blood and urine samples were taken in four moments: before the beginning, in the middle, at the end of the infusion and two hours after. Blood and urine $\mathrm{pH}$, blood $\mathrm{pCO}_{2}, \mathrm{HCO}_{3}^{-}$and $\mathrm{BE}$, and plasma $\mathrm{Na}^{+}, \mathrm{K}^{+}, \mathrm{Cl}, \mathrm{TP}$ and L lactate were measured. $\mathrm{Na}^{+}, \mathrm{K}^{+}, \mathrm{Cl}$ and L lactate fractional clearance and plasma SID, AG, and $A_{\text {tot }}$ were calculated. LRS caused hemodilution but didn't change electrolyte and acid-base balances in healthy ewes. When ewes were affected by ARLA, the infusion of this solution was effective for dehydration reversion but was unable to correct metabolic acidosis.
\end{abstract}

Keywords: fluid therapy, metabolic acidosis, acid-base balance, electrolyte balance

\section{INTRODUÇÃO}

A acidose metabólica é um desequilíbrio acidobase comumente encontrado porque acompanha muitas enfermidades, tais como as diarreias, a acetonemia, os choques hipovolêmico, endotoxêmico e septicêmico, a acidose láctica ruminal aguda e a insuficiência

Recebido em 10 de fevereiro de 2013

Aceito em 30 de julho de 2014

*Autor para correspondência (corresponding author)

E-mail: janlisboa@uel.br renal. É provocada pelo acúmulo dos íons hidrogênio, representando os ácidos, e/ou pela perda dos íons bicarbonato, resultando na queda do $\mathrm{pH}$ sanguíneo e da concentração de bicarbonato (DiBartola, 2006).

A correção da acidose metabólica é realizada por meio da administração de soluções alcalinizantes. A solução que contém bicarbonato 
de sódio é a mais comumente utilizada nos casos de acidose metabólica devido à sua ação imediata. Porém, a quantidade necessária a ser administrada somente pode ser calculada a partir do resultado do exame hemogasométrico (Radostits et al., 2007), e esse recurso não está disponível para o clínico veterinário na maioria das vezes. A utilização de quantidades de bicarbonato de sódio acima do necessário pode provocar efeitos colaterais, como hipernatremia, alcalose iatrogênica, acidose paradoxal do fluido cefalorraquidiano e hemorragia intracraniana (Hartsfield et al., 1981).

Agentes precursores do bicarbonato, como o acetato, o propionato e o lactato podem ser utilizados no tratamento da acidose metabólica (Naylor e Forsyth, 1986). No Brasil, apenas o lactato é encontrado em solução eletrolítica para administração intravenosa, especificamente, na solução de Ringer com lactato (SRL). A SRL é ligeiramente hiposmolar $(275 \mathrm{mOsm} / \mathrm{L})$ e possui composição iônica balanceada, parecida com a do plasma, com $130 \mathrm{mEq} / \mathrm{L}$ de sódio, $109 \mathrm{mEq} / \mathrm{L}$ de cloreto, $4 \mathrm{mEq} / \mathrm{L}$ de potássio, $3 \mathrm{mEq} / \mathrm{L}$ de cálcio e $28 \mathrm{mEq} / \mathrm{L}$ de lactato. O lactato induz alcalinização após metabolização hepática mediante duas vias metabólicas: a gliconeogênese e a via oxidativa, com reações em que os íons $\mathrm{HCO}_{3}^{-}$são produzidos direta ou indiretamente (Constable, 2003).

Evidências preliminares indicam que a SRL não é capaz de aumentar a reserva alcalina em bezerros (Lisbôa et al., 2007) e em ovelhas sadias (Flaiban et al., 2009), e resultados contraditórios foram observados quando se empregou essa solução para o tratamento de animais acidóticos (Mendes Netto e Ortolani, 2000; Nakagawa et al., 2009). O objetivo deste trabalho foi investigar o efeito da SRL sobre os equilíbrios hídrico, eletrolítico e acidobase de ovelhas sadias e após desenvolverem acidose metabólica.

\section{MATERIAL E MÉTODOS}

O protocolo experimental foi aprovado pelo Comitê de Ética em Experimentação Animal da UEL (CEEA/UEL) sob o número de registro 40/07. Foram utilizadas seis ovelhas, mestiças, adultas, clinicamente sadias e com peso corporal de $43,1 \pm 4,9 \mathrm{~kg}$, não gestantes e não lactantes, pertencentes ao rebanho do Hospital Veterinário da UEL. Os animais foram submetidos a um confinamento em baia coletiva e período de adaptação à dieta de 30 dias. Durante todo o período experimental receberam 400 gramas de ração comercial por dia, oferecidos em duas porções diárias, e feno de capim coast-cross (Cynodon dactylon), sal mineral e água à vontade.

Inicialmente as ovelhas receberam a solução comercial de Ringer com lactato (Ringer com Lactato; Fresenius Kabi Brasil Ltda.) (SRL) infundida por via intravenosa, por meio de um cateter $18 \mathrm{G}$, fixado na veia jugular esquerda e removido ao final da infusão. $\mathrm{O}$ volume administrado foi equivalente a $10 \%$ do peso corporal, e a infusão foi contínua durante 4 horas, mantendo-se a velocidade de $25 \mathrm{~mL} / \mathrm{kg} / \mathrm{h}$.

Após o período mínimo de sete dias, as mesmas ovelhas foram submetidas à indução de acidose láctica ruminal aguda (ALRA), obedecendo a protocolo já estabelecido (Kezar e Church, 1979), que consiste na administração intrarruminal de sacarose (Açúcar Cristal Estrela; LDC Bioernergia S.A.), na dose de $15 \mathrm{~g} / \mathrm{kg}$ de peso corporal diluídos em água aquecida $\left(39^{\circ} \mathrm{C}\right)$, por meio de sondagem esofageana. Antes da indução, as ovelhas foram mantidas privadas de alimento por 18 horas, com livre acesso a água. Após a indução, exames físicos foram realizados a cada duas horas para acompanhar a evolução da doença.

O tratamento das ovelhas acidóticas iniciou-se 16 horas após a indução e consistiu na remoção do suco ruminal repleto de ácido láctico e na infusão intravenosa da SRL. A SRL foi administrada nas seis ovelhas acidóticas, obedecendo ao mesmo protocolo de volume e velocidade de infusão adotado enquanto estavam sadias.

Dois procedimentos de lavagens ruminais, por meio de sondagem esofageana, foram realizados nas ovelhas com ALRA com a finalidade de remover a maior parte possível do suco ruminal acumulado e repleto de ácido láctico. A primeira lavagem foi realizada antes da infusão intravenosa da SRL, e a segunda ocorreu após a última colheita de amostras, 2 horas após o término da infusão. $\mathrm{O}$ procedimento era iniciado com a drenagem espontânea de suco ruminal auxiliada por compressão manual do abdômen. Após a colheita dessa amostra de suco ruminal 
que se destinava à mensuração do pH, a lavagem propriamente dita era realizada e consistia na administração de $4 \mathrm{~L}$ de água morna para o interior do rúmen, massagens externas do abdômen e sifonamento posterior de todo o volume introduzido auxiliado pela compressão manual do abdômen. Esse procedimento foi repetido quatro vezes totalizando $16 \mathrm{~L}$ na primeira lavagem, e três vezes totalizando $12 \mathrm{~L}$ na segunda lavagem.

Após o término da infusão da SRL, a oferta de feno foi restabelecida e o comportamento de ingestão voluntária foi acompanhado. Exames físicos foram realizados 2, 4, 8 e 12 horas após o término na infusão, a cada 8 horas no segundo e no terceiro dia e a cada 12 horas até o quinto dia.

Amostras de sangue venoso foram colhidas por punção da veia jugular e amostras de urina foram colhidas por micção espontânea ou induzida por asfixia breve nos seguintes momentos: imediatamente antes do início da infusão, na metade do volume administrado, ao término da infusão e duas horas após o término. Nas ovelhas com ALRA, colheitas adicionais de sangue para exame hemogasométrico foram realizadas 4,8 , 12 e 20 horas após o término da infusão. Esse último momento correspondia a 24 horas após o início do tratamento.

As amostras destinadas ao exame hemogasométrico foram colhidas respeitando-se todos os cuidados necessários para impedir o contato do sangue com o ar atmosférico (Lisbôa et al., 2002). Foi utilizada agulha descartável $25 \times 0,8 \mathrm{~mm}$, acoplada a uma seringa plástica de $3 \mathrm{~mL}$ contendo aproximadamente 400UI de heparina sódica (Heparin; Cristália - Produtos Químicos e Farmacêuticos Ltda.).
As outras duas amostras de sangue foram colhidas empregando-se frascos a vácuo contendo fluoreto de sódio para a obtenção do plasma, e frascos a vácuo sem anticoagulante para a obtenção do soro. O plasma foi obtido por meio de centrifugação imediatamente após a colheita. O soro sanguíneo foi obtido por centrifugação após a retração do coágulo. As amostras de soro e de plasma foram conservadas por congelamento $\left(20^{\circ} \mathrm{C}\right.$ negativos) até o momento do processamento.

As determinações sanguíneas de $\mathrm{pH}$, pressão parcial de dióxido de carbono $\left(\mathrm{pCO}_{2}\right)$, bicarbonato $\left(\mathrm{HCO}_{3}{ }^{-}\right)$e excesso de bases (BE) foram realizadas em analisador de gases sanguíneos (Omni C; Roche). As concentrações séricas e urinárias de sódio $\left(\mathrm{Na}^{+}\right)$, potássio $\left(\mathrm{K}^{+}\right)$e cloretos $\left(\mathrm{Cl}^{-}\right)$foram determinadas pelo método de eletrodo íon seletivo (Dimension Clinical Chemistry System, Dade Behring; Siemens). Para a mensuração da concentração plasmática e urinária do lactato $\mathrm{L}$, foi utilizado o método enzimático colorimétrico empregando reagente comercial específico (Lactato; Bioclin; Química Básica Ltda.) e leitura espectrofotométrica (Bio 2000; Bioplus). As concentrações de creatinina sérica e urinária foram mensuradas pelo método cinético (Creatinina; Bioclin; Química Básica Ltda.) com leitura espectrofotométrica.

A concentração das proteínas plasmáticas totais (PPT) e a densidade urinária foram mensuradas por refratometria. $\mathrm{O} \mathrm{pH}$ do suco ruminal e o da urina foram mensurados com potenciômetro eletrônico (pHmeter Tec-2, Tecnal).

A partir das variáveis mensuradas, foram calculadas as seguintes variáveis, empregando-se as fórmulas correspondentes:

Hiato aniônico - Anion Gap (AG) (DiBartola, 2006): $\mathrm{AG}=\left(\mathrm{Na}^{+}+\mathrm{K}^{+}\right)-\left(\mathrm{Cl}^{-}+\mathrm{HCO}_{3}{ }^{-}\right)$

Diferença de íons fortes - Strong Ion Difference (SID) (Constable, 1997): SID $=\left(\mathrm{Na}^{+}+\mathrm{K}^{+}\right)-\left(\mathrm{Cl}^{-}\right)$

Concentração total de ácidos fracos não voláteis $-\mathrm{A}_{\text {tot }}$ (Las et al., 2007): $\mathrm{A}_{\text {tot }}=\mathrm{PPT}(\mathrm{g} / \mathrm{dL}) \times 2,9$

Excreção fracionada de eletrólitos e de lactato (Garry et al., 1990):

$$
\mathrm{EF}(\mathrm{a})=\frac{\text { Concentração urinária de (a) } \text { x creatinina plasmática }}{\text { Concentração plasmática de (a) } \text { x creatinina urinária }} \times 100
$$

em que (a) é a substância excretada.

Adotou-se o delineamento experimental crossover. A análise de variâncias de medidas repetidas bifatorial foi empregada para testar os efeitos do volume infundido, do estado acidobase (sadias $\mathrm{x}$ acidóticas) e da interação entre esses dois fatores. Quando a estatística $\mathrm{F}$ resultou significativa, o teste Tukey foi empregado para comparação entre as médias. Admitiu-se uma 
probabilidade de erro de 5\%. O programa SigmaStat for Windows 3.1 foi utilizado para a análise estatística.

\section{RESULTADOS E DISCUSSÃO}

O protocolo experimental utilizado para a indução de acidose láctica ruminal aguda (ALRA) foi bem-sucedido, provocando a acidose metabólica sistêmica esperada e necessária para o estudo proposto. Após a administração da sacarose, o distúrbio fermentativo pré-estomacal se desenvolveu e agravou gradativamente. Dezesseis horas após a indução, as ovelhas exibiam apatia, desidratação moderada, mucosas de cor vermelha, normotermia $\left(39,1 \pm 0,7^{\circ} \mathrm{C}\right)$, frequências cardíaca $(118,6 \pm 11,0 \mathrm{bpm})$ e respiratória $(30,0 \pm 5,69 \mathrm{mpm})$ dentro dos intervalos fisiológicos, atonia ruminal, diarreia (fezes pastosas a liquefeitas) e distensão abdominal leve relacionada à dilatação ruminal com líquido; porém, sem timpanismo. Esses são sinais esperados para a enfermidade induzida e foram complementados pelo $\mathrm{pH}$ reduzido do suco ruminal $(4,30 \pm 0,11)$, caracterizando o grau intenso de ALRA, segundo a classificação de Underwood (1992).

A acidose metabólica sistêmica já estava presente e os seguintes valores foram observados logo antes de se iniciar o tratamento: $7,260 \pm 0,090$ para o $\mathrm{pH}, 16,72 \pm 4,81 \mathrm{mmol} / \mathrm{L}$ para o $\mathrm{HCO}_{3}^{-},-9,58 \pm 5,76 \mathrm{mmol} / \mathrm{L}$ para o $\mathrm{BE}$ e $36,95 \pm 3,58 \mathrm{mmHg}$ para a $\mathrm{pCO}_{2}$ no sangue venoso. Esses resultados indicam que as ovelhas desenvolveram grau moderado de acidemia (Radostits et al., 2007) e de acidose metabólica (Underwood, 1992). A compensação respiratória não foi evidente nesse momento inicial de colheita de amostras, mas estava presente nos momentos seguintes, com valores médios da $\mathrm{pCO}_{2}$ que variaram de 32,10 a $32,85 \mathrm{mmHg}$ e eram menores $(\mathrm{P}<0,05)$ do que os mensurados enquanto estavam sadias (Fig. 1). O lactato L não estava elevado $(2,90 \pm 1,21 \mathrm{mmol} / \mathrm{L})$ e não diferia do observado quando as ovelhas eram sadias ( $\mathrm{P}>0,05)$. O lactato D não foi mensurado, mas, a julgar pelo valor muito elevado do $A G$ $(22,95 \pm 7,89 \mathrm{mmol} / \mathrm{L})$, pode-se supor que a hiperlactatemia D estivesse presente como a causa determinante da acidose metabólica (Maruta e Ortolani, 2002). Em sua condição de higidez, as ovelhas apresentavam valores do AG duas vezes menores $(10,79 \pm 6,30 \mathrm{mmol} / \mathrm{L})$ $(\mathrm{P}<0,001)$. Como mecanismo de resposta para a tentativa de correção do desequilíbrio acidobase (Maruta et al., 2008), as ovelhas com ALRA passaram a eliminar urina ácida ( $\mathrm{pH}$ de $6,073 \pm 0,432)(\mathrm{P}<0,001)$.

A ALRA induzida não provocou desequilíbrio eletrolítico e, exceto a concentração sérica de $\mathrm{Cl}^{-} \quad(113,03 \pm 6,70 \mathrm{mmol} / \mathrm{L}), \quad$ ligeiramente menor nas ovelhas enquanto acidóticas $(\mathrm{P}<0,01)$, as de $\mathrm{Na}^{+}(148,28 \pm 2,64 \mathrm{mmol} / \mathrm{L})$ e de $\mathrm{K}^{+}(4,42 \pm 1,15 \mathrm{mmol} / \mathrm{L})$, bem como a SID $(39,67 \pm 8,26 \mathrm{mmol} / \mathrm{L})$, não se modificaram com a doença $(\mathrm{P}>0,05)$. Curiosamente, a hemoconcentração relacionada à desidratação das ovelhas doentes não foi acompanhada por hiperproteinemia $(6,97 \pm 0,87 \mathrm{~g} / \mathrm{dL})$ e a $\mathrm{A}_{\text {tot }}$ $(20,20 \pm 2,53 \mathrm{mmol} / \mathrm{L})$ acabou não diferindo entre as ovelhas acidóticas e sadias $(\mathrm{P}>0,05)$. A eliminação de urina mais concentrada (densidade

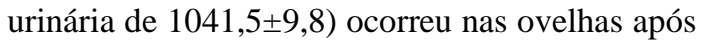
desenvolverem ALRA $(\mathrm{P}<0,05) \quad$ como mecanismo para conservação de água no organismo em resposta à desidratação.

A infusão da SRL em volume correspondente a $10 \%$ do peso corporal nas ovelhas enquanto estavam sadias não provocou alterações nos equilíbrios acidobase e eletrolítico. $\mathrm{O} \mathrm{pH}, \mathrm{o}$ $\mathrm{HCO}_{3}{ }^{-}$, o $\mathrm{BE}$ e a $\mathrm{pCO}_{2}$ sanguíneos (Fig. 1) e o $\mathrm{pH}$ da urina (Fig. 3) mantiveram-se estáveis durante e após a administração intravenosa $(\mathrm{P}>0,05)$. As concentrações séricas de $\mathrm{Na}^{+}$e de $\mathrm{Cl}^{-}$se elevaram discretamente com a infusão, mas as de $\mathrm{K}^{+}$e a SID não se modificaram (Fig. 2). As excreções fracionadas de $\mathrm{Na}^{+}$e de $\mathrm{Cl}^{-}$ aumentaram $(\mathrm{P}<0,001)$ durante a infusão como mecanismo necessário para a eliminação do excesso administrado e manutenção da homeostase (Fig. 3). E ainda que a SRL utilizada apresentasse o lactato $\mathrm{L}$ representando $93 \%$ de todo o lactato presente, a concentração plasmática e a excreção fracionada de lactato $\mathrm{L}$ não sofreram efeito da administração da solução ( $\mathrm{P}>0,05)$. Isso reforça evidências preliminares, em ovelhas sadias (Flaiban et al., 2009) e em bezerros sadios (Lisbôa et al., 2007), de que a SRL não possui efeito alcalinizante e não interfere no equilíbrio eletrolítico. 
$\mathrm{pH}$

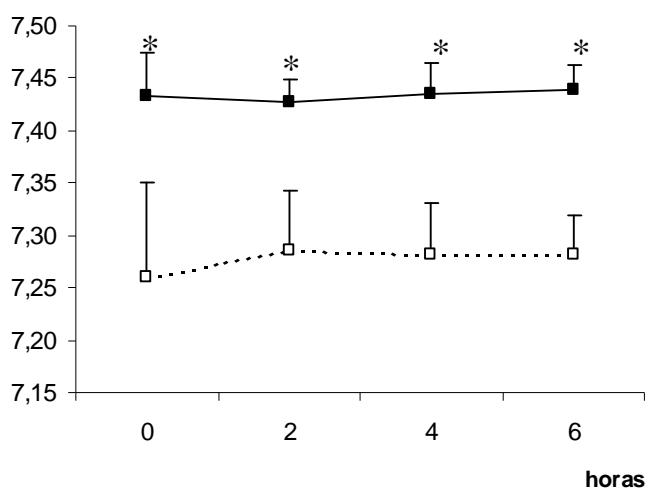

$\mathrm{HCO}_{3}^{-}$

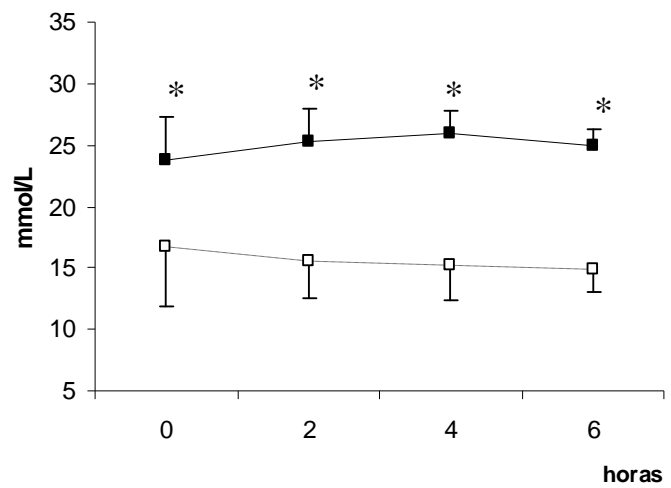

$\mathrm{pCO}_{2}$

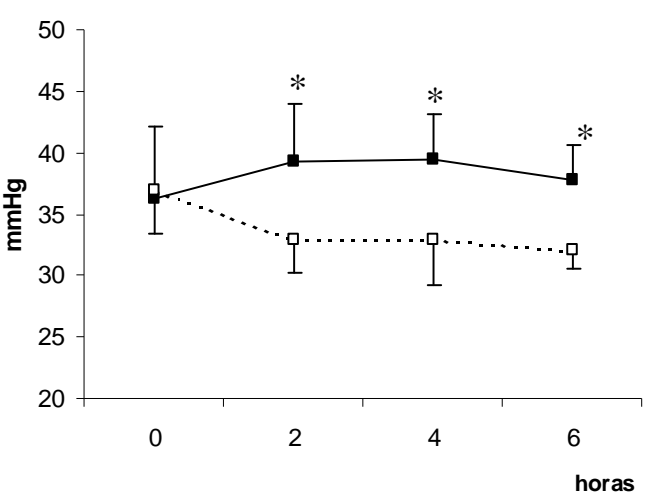

BE

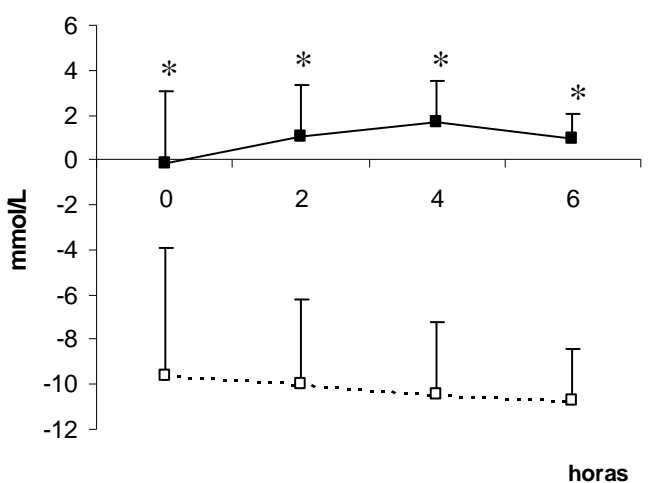

Figura 1. Variações do $\mathrm{pH}$, da pressão de dióxido de carbono $\left(\mathrm{pCO}_{2}\right)$, da concentração do bicarbonato $\left(\mathrm{HCO}_{3}{ }^{-}\right)$e do excesso de bases (BE) no sangue venoso de ovelhas sadias (-) e após desenvolverem acidose metabólica (---) que receberam a administração intravenosa da solução de Ringer com lactato em volume correspondente a $10 \%$ do peso corporal durante 4 horas de infusão contínua. (*) A marcação indica diferença entre as médias em cada momento $\left(\mathrm{P}<0,05\right.$ para a $\mathrm{pCO}_{2}$; e $\mathrm{P}<0,001$ para as demais variáveis).

Com exceção do sódio sérico que se reduziu no meio da infusão e se manteve menor (Fig. 2), as demais variáveis estudadas apresentaram exatamente o mesmo comportamento já descrito para as ovelhas sadias, quando elas estavam acidóticas e foram tratadas com a SRL (Fig. 1, 2 e 3).

As ovelhas mantiveram o mesmo grau de desequilíbrio acidobase, exibindo, em todos os momentos, valores de $\mathrm{pH}, \mathrm{HCO}_{3}^{-}, \mathrm{BE}$ e $\mathrm{pCO}_{2}$ sanguíneos (Fig. 1) e de pH urinário (Fig. 3) sempre mais baixos $(\mathrm{P}<0,001)$ do que os que apresentavam quando estavam sadias. $\mathrm{O} A \mathrm{AG}$, ao contrário, sempre esteve mais alto $(\mathrm{P}<0,001)$ quando as ovelhas estavam doentes. A SRL administrada foi, portanto, incapaz de promover a correção da acidose metabólica, e duas horas após o término da infusão as ovelhas apresentavam os seguintes valores: 7,281 $\pm 0,038$ para o $\mathrm{pH}, 14,87 \pm 1,83 \mathrm{mmol} / \mathrm{L}$ para o $\mathrm{HCO}_{3}{ }^{-}$, $10,77 \pm 2,29 \mathrm{mmol} / \mathrm{L}$ para o $\mathrm{BE} \quad \mathrm{e}$ $32,10 \pm 1,52 \mathrm{mmHg}$ para a $\mathrm{pCO}_{2}$ sanguíneos; $14,67 \pm 2,97 \mathrm{mmol} / \mathrm{L}$ para o $\mathrm{AG}$, e $5,650 \pm 0,286$ para o $\mathrm{pH}$ urinário.

A concentração de $\mathrm{K}^{+}$no soro e a SID não se alteraram com o tratamento $(\mathrm{P}>0,05)$ e não foram diferentes nas ovelhas enquanto sadias ou doentes $(\mathrm{P}>0,05) . \mathrm{O} \mathrm{Cl}^{-}$, por outro lado, se 
elevou com a infusão, mas sempre esteve em concentração menor nas ovelhas quando acidóticas $(\mathrm{P}<0,01)$ (Fig. 2). Essa diferença poderia ser explicada pela relação de interdependência existente entre o $\mathrm{HCO}_{3}{ }^{-}$e o $\mathrm{Cl}^{-}$. Nos estados de acidose metabólica, os rins aumentam a excreção de ácidos $\left(\mathrm{H}^{+}\right)$e a conservação do $\mathrm{HCO}_{3}{ }^{-}$como o mecanismo natural para tentar reverter o desequilíbrio. A reabsorção de $\mathrm{Na}^{+}$e a eliminação de $\mathrm{Cl}^{-}$ acompanham esses eventos obrigatoriamente

$\mathrm{Na}^{+}$

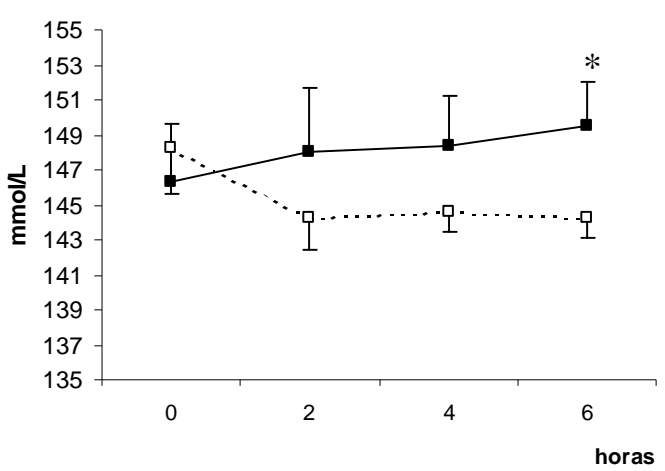

$\mathrm{K}^{+}$

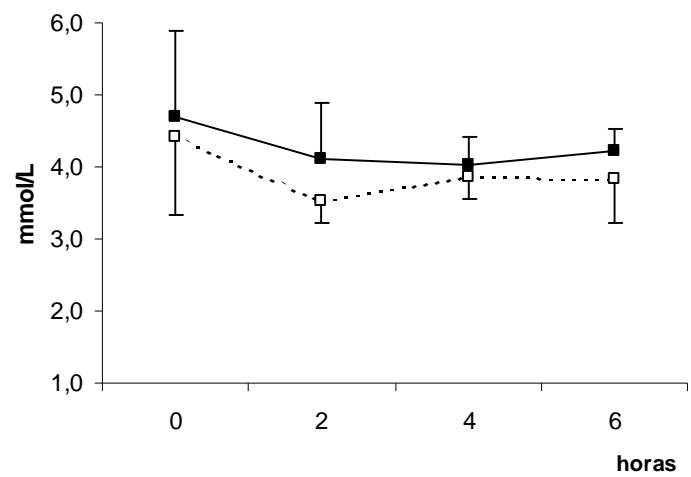

(DiBartola, 2006). Com a infusão da SRL e a correção da desidratação, o mecanismo renal de excreção seletiva de eletrólitos pôde ser otimizado, aumentando a excreção fracionada de $\mathrm{Cl}^{-}$(Fig. 3). A de $\mathrm{Na}^{+}$também se elevou, provavelmente como reflexo do restabelecimento do equilíbrio hídrico ao final da infusão, tornando menos necessária a retenção desse íon para a conservação de água no organismo (Garry et al., 1990).

$\mathrm{Cl}^{-}$

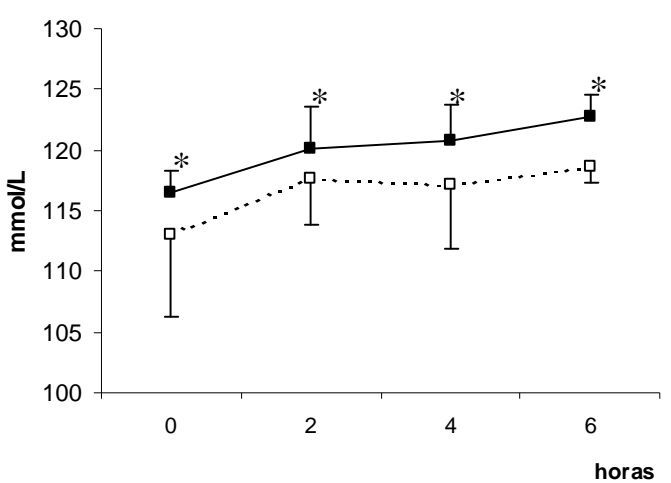

SID

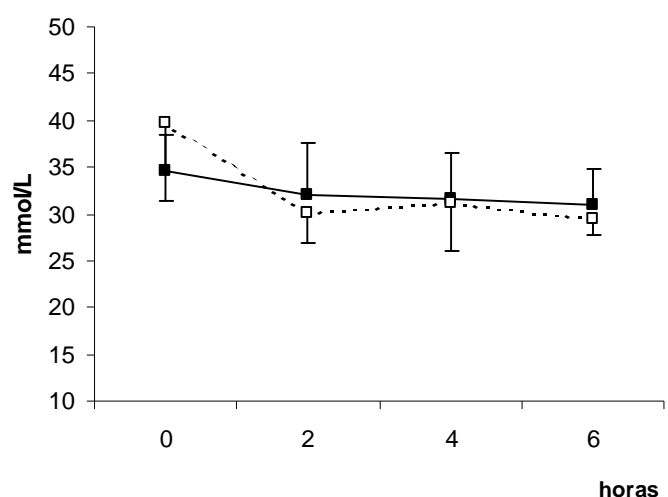

Figura 2. Variações das concentrações de sódio $\left(\mathrm{Na}^{+}\right)$, cloretos $\left(\mathrm{Cl}^{-}\right)$e potássio $\left(\mathrm{K}^{+}\right)$e da diferença de íons fortes (SID) no soro sanguíneo de ovelhas sadias (-) e após desenvolverem acidose metabólica (---), que receberam a administração intravenosa da solução de Ringer com lactato em volume correspondente a $10 \%$ do peso corporal durante 4 horas de infusão contínua. (*) A marcação indica diferença entre as médias em cada momento $\left(\mathrm{P}<0,05\right.$ para o $\mathrm{Na}^{+}$; e $\mathrm{P}<0,01$ para o $\left.\mathrm{Cl}^{-}\right)$. 
EF $\mathrm{Na}^{+}$

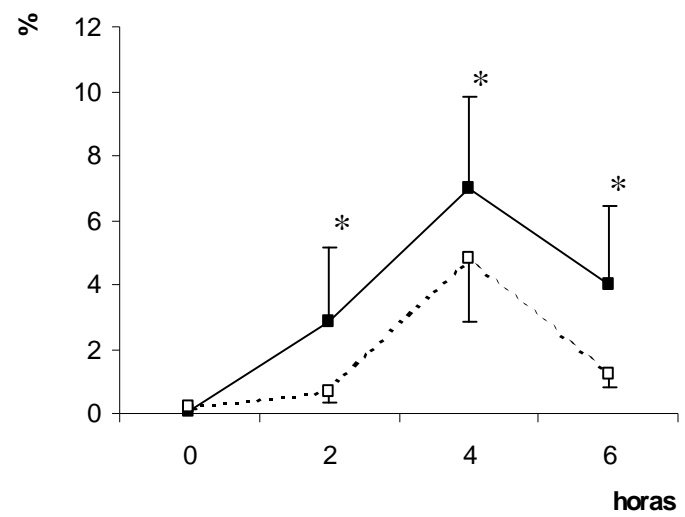

EF $\mathbf{K}^{+}$

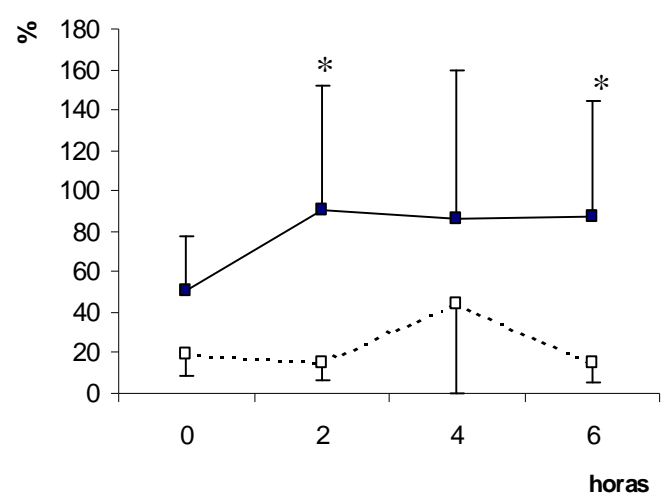

$\mathrm{EFCl}^{-}$

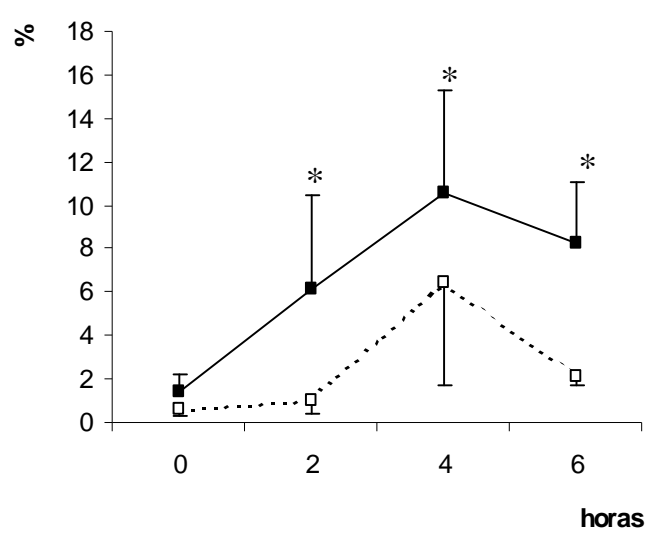

$\mathrm{pH}$

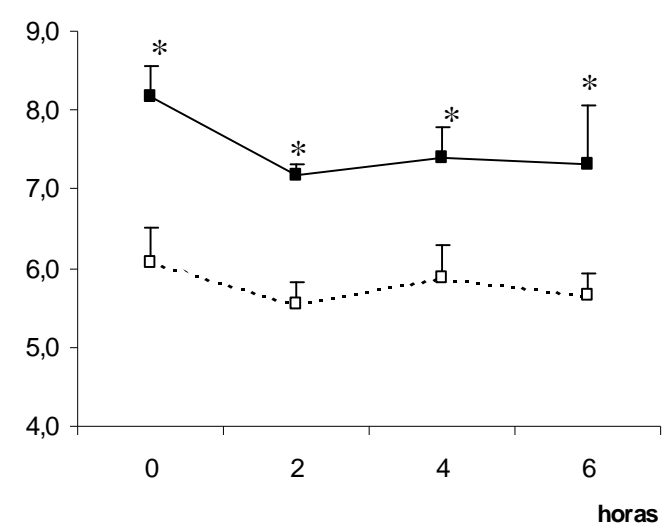

Figura 3. Variações das excreções fracionadas urinárias de sódio $\left(\mathrm{EF} \mathrm{Na}^{+}\right)$, de cloretos $\left(\mathrm{EF} \mathrm{Cl}^{-}\right)$e de potássio $\left(\mathrm{EF} \mathrm{K}^{+}\right)$e do $\mathrm{pH}$ urinário de ovelhas sadias (-) e após desenvolverem acidose metabólica (---), que receberam a administração intravenosa da solução de Ringer com lactato em volume correspondente a $10 \%$ do peso corporal durante 4 horas de infusão contínua. (*) A marcação indica diferença entre as médias em cada momento ( $\mathrm{P}<0,001$ para o $\mathrm{pH}$; e $\mathrm{P}<0,01$ para as demais variáveis).

A desidratação que apresentavam por causa da ALRA foi efetivamente corrigida com o volume administrado, e os valores de PPT, $A_{\text {tot }}$ e AG tornaram-se menores e assim se mantiveram a partir da metade da infusão $(P<0,001)$. Com o retorno ao equilíbrio, passaram a eliminar urina menos concentrada, e a densidade urinária diminuiu gradualmente até o final da infusão $(\mathrm{P}<0,001)$. As mucosas retornaram à sua cor rosa clara e voltaram a se apresentar úmidas; a enoftalmia leve foi revertida e a elasticidade da pele, restabelecida.
Após as lavagens ruminais e não mais desidratadas, as ovelhas começaram a demonstrar interesse pelo feno oferecido, mas mantiveram a ingestão de pequena quantidade e apatia leve ao longo de todo o dia do tratamento. As avaliações hemogasométricas comprovaram que a acidose metabólica não compensada se manteve presente durante aquele dia, e confirmaram que o tratamento baseado na remoção do ácido láctico acumulado no interior do rúmen e na correção da desidratação foi insuficiente para minimizar o desequilíbrio acidobase. No dia seguinte ao tratamento (24 horas após o início da infusão intravenosa), as 
ovelhas mantinham-se levemente apáticas, e o desequilíbrio ainda estava presente. Os seguintes valores foram observados no sangue venoso: $7,222 \pm 0,040$ para o $\mathrm{pH}, 12,40 \pm 1,80 \mathrm{mmol} / \mathrm{L}$ para o $\mathrm{HCO}_{3}^{-},-14,0 \pm 1,12 \mathrm{mmol} / \mathrm{L}$ para o $\mathrm{BE}$ e $31,0 \pm 3,80 \mathrm{mmHg}$ para a $\mathrm{pCO}_{2}$.

Nesse momento, as ovelhas foram tratadas com 1L da solução de bicarbonato de sódio 1,3\% administrado por via intravenosa durante 4 horas de infusão contínua, com a finalidade de corrigir a acidose metabólica que persistia. O objetivo foi alcançado e as ovelhas apresentavam os seguintes valores após o tratamento: 7,382 $\pm 0,020$ para o $\mathrm{pH}, 20,0 \pm 1,40 \mathrm{mmol} / \mathrm{L}$ para $\mathrm{o}_{\mathrm{HCO}_{3}}{ }^{-}$, $4,30 \pm 1,47 \mathrm{mmol} / \mathrm{L}$ para o BE e $34,40 \pm 1,80 \mathrm{mmHg}$ para a $\mathrm{pCO}_{2}$. Ao longo dos quatro dias seguintes, todas as ovelhas apresentaram melhora gradativa e recuperaram a saúde no quarto dia após o primeiro tratamento.

Os resultados deste estudo confirmam que a SRL não produziu aumento da reserva alcalina nas ovelhas sadias e que a necessidade imposta pela acidose metabólica, após desenvolverem ALRA, não modificou o efeito dessa solução eletrolítica. Apesar de a SRL ser popularmente considerada uma solução com potencial alcalinizante e frequentemente indicada para o tratamento de animais portadores de acidose metabólica, fica claro que esses conceitos são contestáveis. De fato, a SRL foi absolutamente ineficaz para a correção do desequilíbrio acidobase nas ovelhas estudadas. Isso reforça um estudo prévio com bezerros acidóticos (Nakagawa et al., 2009), mas contraria parcialmente observação anterior em garrotes com ALRA induzida (Mendes Netto e Ortolani, 2000). Semelhantemente ao estudo presente, os garrotes tratados com SRL por esses autores continuavam acidóticos ao término da infusão. No dia seguinte, contudo, já se aproximavam da condição de equilíbrio.

A ausência de efeito alcalinizante da SRL devese à concentração reduzida do lactato presente $(28 \mathrm{mEq} / \mathrm{L})$ e ao fato de possuir uma composição eletrolítica que se aproxima da do plasma (Constable, 2003), o que também explica a ausência de interferência dessa solução no equilíbrio eletrolítico dos animais. Quando a concentração de lactato foi duplicada ou triplicada na solução, o potencial alcalinizante foi proporcionalmente incrementado em ovelhas sadias (Flaiban et al., 2009). Estudos anteriores, que empregaram solução de lactato de sódio contendo concentração de lactato $(150 \mathrm{mEq} / \mathrm{L})$ cinco vezes maior do que a da SRL, comprovaram alcalinização muito eficiente em bezerros (Naylor e Forsyth, 1986) e em garrotes (Leal et al., 2007a) sadios.

Kasari e Naylor (1985) demonstraram que o efeito tamponante do lactato em solução estava comprometido nos bezerros acidóticos porque a metabolização não era tão eficiente quanto à dos bezerros hígidos. E conforme afirmação de Constable (2003), seria incoerente utilizar soluções contendo lactato para corrigir a acidose metabólica em animais que possuem hiperlactatemia como causa do desequilíbrio. Essas justificativas não podem ser aceitas como explicação para a ineficácia da SRL observada neste estudo. Em garrotes e em ovelhas acometidos por ALRA induzida experimentalmente, soluções contendo $150 \mathrm{mEq} / \mathrm{L}$ e $84 \mathrm{mEq} / \mathrm{L}$ de lactato, respectivamente, foram capazes de promover a correção da acidose metabólica com eficiência (Leal et al., 2007b; Flaiban et al., 2010).

\section{CONCLUSÃO}

A solução de Ringer com lactato, administrada em volume correspondente a $10 \%$ do peso corporal, não interferiu nos equilíbrios eletrolítico e acidobase das ovelhas sadias e, apesar de eficiente para reverter a desidratação quando as ovelhas foram acometidas por acidose láctica ruminal aguda, foi ineficaz para corrigir a acidose metabólica presente.

\section{REFERÊNCIAS}

CONSTABLE, P.D. A simplified strong ion model for acid-base equilibra: application to horse plasma. $J$. Appl. Physiol., v.83, p.297-311, 1997.

CONSTABLE, P.D. Fluid and electrolyte therapy in ruminants. Vet. Clin. Food Anim., v.19, p.557-597, 2003.

DiBARTOLA, S.P. Introduction to acid-base disorders. In:__. (Ed). Fluid, electrolyte, and acid-base disorders in small animal practice. 3 .ed. St Louis: Saunders Elsevier, 2006. p.229-251.

FLAIBAN, K.K.M.C.; FERNANDES, L.I.; PEZENTI, E.M. et al. Sodium lactate concentrated solution can correct metabolic acidosis due to induced acute rumen lactic acidosis. In: WORLD BUIATRICS CONGRESS, 26., 2010, Santiago. Proceeding... Santiago: Novodiseño, 2010. p.374. (Abstract). 
FLAIBAN, K.K.M.C.; ROMÃO, F.T.N.M.A.; SILVA, R.S. et al. Potencial alcalinizante de soluções intravenosas de lactato e de bicarbonato de sódio administradas em ovelhas sadias. Cienc. Anim. Bras., v.10, Supl. 1, p.176-180, 2009.

GARRY, F.; CHEW, D.J.; RINGS, D.M. et al. Renal excretion of creatinine, electrolytes, protein, and enzymes in healthy sheep. Am. J. Vet. Res., v.51, p.414-419, 1990.

HARTSFIELD, S.M.; THURMON, J.; BENSON, G. Sodium bicarbonate and bicarbonate precursors for treatment of metabolic acidosis. J. Am. Vet. Med. Assoc., v.179, p.914-916, 1981.

KASARI, T.R.; NAYLOR, J.M. Clinical evaluation of sodium bicarbonate, sodium L-lactate, and sodium acetate for the treatment of acidosis in diarrheic calves. J. Am. Vet. Med. Assoc., v.187, p.392-397, 1985.

KEZAR, W.W.; CHURCH, D.C. Ruminal changes during the onset and recovery of induced lactic acidosis in sheep. J. Anim. Sci., v.49, p.1161-1167, 1979.

LAS, J.E.; ODONGO, N.E.; LINDINGER, M.I. et al. Effects of dietary strong acid anion challenge on regulation of acid-base balance in sheep. J. Anim. Sci., v.85, p.2222-2229, 2007.

LEAL, M.L.R.; MORI, C.S.; ORTOLANI, E.L. Estudo da capacidade alcalinizante de tampões metabolizáveis em bovinos sadios. Arq. Bras. Med. Vet. Zootec., v.59, p.965-970, 2007a.

LEAL, M.L.R.; MARUTA, C.A.; ORTOLANI, E.L. Uso de bicarbonato e lactato-L para correção da acidose metabólica sistêmica em bovinos com acidose láctica ruminal aguda. Arq. Bras. Med. Vet. Zootec., v.59, p.971-976, 2007b.

LISBÔA, J.A.N.; BENESI, F.J.; LEAL, M.L.R. et al. Efeito da idade sobre o equilíbrio àcido-básico de bezerras sadias no primeiro mês de vida. Braz. J. Vet. Res. Anim. Sci., v.39, p.136-42, 2002.
LISBÔA, J.A.N.; FLAIBAN, K.K.M.C.; LANDMAN, M.L.L. et al. Potencial alcalinizante da solução de Ringer com lactato em bezerros sadios. Arch. Vet. Sci., v.12, Suplemento, p.90-91, 2007.

MARUTA, A.C.; LEAL, M.L.R.; MENDES NETTO, D. et al. The measurement of urine $\mathrm{pH}$ to predict the amount of buffer used in the treatment of acute rumen lactic acidosis in cattle. Cienc. Rural, v.38, p.717-722, 2008.

MARUTA, C.A.; ORTOLANI, E.L. Suscetibilidade de bovinos das raças Jersey e Gir à

acidose láctica ruminal: Acidose metabólica e metabolização do L-lactato. Cienc. Rural, v.32, p.6165, 2002.

MENDES NETTO, D.; ORTOLANI, E.L. Evaluation of sodium bicarbonate or lactated Ringer's solution for the treatment of rumen lactic acidosis in steers. Vet. Not., v.6, p.31-39, 2000.

NAKAGAWA, M.; SUZUKI, K.; TAKAHASHI, F. et al. Comparison of the alkalizing effects of bicarbonate precursors in calves with experimentally induced metabolic acidosis. J. Vet. Med. Sci., v.71, p.807-809, 2009.

NAYLOR, J.M.; FORSYTH, G.M. The alkalinizing effects os metabolizable bases in the healthy calf. Can. J. Vet. Res., v.50, p.509-516, 1986.

RADOSTITIS, O.M.; GAY, C.C.; HINCHCLIFF, K.W.; CONSTABLE, P.D. (Ed). Veterinary Medicine. A textbook of the diseases of cattle, horses, sheep, pigs, and goats. 10.ed. Edinburgh: Saunders Elsevier, 2007. 2156p.

UNDERWOOD, W.J. Rumen lactic acidosis: Part IIClinical signs, diagnosis, treatment and prevention. Comp. Cont. Educ. Pract., v.14, p.1265-1271, 1992. 